\title{
Sports Specific Injury Pattern of Sportspersons
}

\author{
Hemantajit Gogoi ${ }^{1, *}$, Yajuvendra Singh Rajpoot ${ }^{2}$, A. S. Sajwan ${ }^{1}$ \\ ${ }^{1}$ Department of Sports Biomechanics, Lakshmibai National Institute of Physical Education, India \\ ${ }^{2}$ Department of Physical Education Pedagogy, Lakshmibai National Institute of Physical Education, India
}

Received July 14, 2020; Revised September 14, 2020; Accepted September 29, 2020

\section{Cite This Paper in the following Citation Styles}

(a): [1] Hemantajit Gogoi, Yajuvendra Singh Rajpoot, A. S. Sajwan , "Sports Specific Injury Pattern of Sportspersons," International Journal of Human Movement and Sports Sciences, Vol. 8, No. 5, pp. 199 - 210, 2020. DOI: 10.13189/saj.2020.080507.

(b): Hemantajit Gogoi, Yajuvendra Singh Rajpoot, A. S. Sajwan (2020). Sports Specific Injury Pattern of Sportspersons. International Journal of Human Movement and Sports Sciences, 8(5), 199 - 210. DOI: 10.13189/saj.2020.080507.

Copyright $@ 2020$ by authors, all rights reserved. Authors agree that this article remains permanently open access under the terms of the Creative Commons Attribution License 4.0 International License

\begin{abstract}
Objective: Previous researches on sports injuries primarily focused on specific games or sports or on specific types of injuries. None of them had tried to explore the injury patterns of games and sports altogether. The current study tried to explore the injury patterns of sportspersons over 16 different types of games and sports. Materials and methods: Total of 1008 injury cases (649 male and 369 female, age $21.07 \pm 2.78$ and $20.81 \pm 3.01$ years) between the academic sessions 2008 to 2017 were analysed. Injury data were extracted from the institute injury record book. Apart from age and gender, ' Body site of injury ', ' Types of injury ' and ' Recurring of injury ' were selected as variables for the study. Descriptive statistics, bar and pie diagram were generated using crosstabs function of IBM SPSS. Results: An average 101.80 \pm 12.59 injury was reported per year. Footballers were found to be the highest injured sportsperson (19.5\%). Injury percentage of male players (63.75\%) was higher compared to female (36.25\%) counterparts. Lower limb area (45.28\%) was found to be the highest affected body site of injury followed by upper limb area (29.47\%). Acute injury constituted $50.39 \%$ of overall injuries. Most injuries were non-recurring in nature (63.65\%). Further different combinations of analysis revealed more insight of injury patterns of sportspersons.
\end{abstract}

Keywords Sports Injury, Types of Injury, Body Site of Injury, Recurring of Injury

\section{Introduction}

Modern sports have been so popular, organized, and important that, no period of world sports history can be compared with the present status of sports. Rules and regulations are now clear, unified methods are derived for objective comparisons of achievements. Sporting achievements become standards for the assessment of the human potential and at the same time play a role in the further development of landmarks. As sports grew and success became a goal, people began to think about how to enhance their performance. The idea of scientific training for sports came to the human mind in the constant desire to expand the boundaries of human performance. Gradually training becomes organized and systematic to improve the individual's physical, psychological, and intellectual performance capacity but at the same time, the physical and emotional burden on players have been intensified[1]. Higher rate of exposure and innovative training develops better performer but at the same time, it becomes the cause of injury among sportspersons.

Sports injury can be simply defined as the injuries which are associated with exercise and sports activities[2]. Participation in games and sports carries an inherent risk of getting injuries. Even the spectators can be injured in sporting events. Conrad [3] had rightly said:

" Whether one is a professional athlete or a weekend warrior, almost every participant incurs physical injury at one time or another. "

Along with increasing young participants in competitive sports; rise in the number of sports-related injuries has also been observed [4,5]. Experts have classified injuries based on affected body region [6] and some had classified based on events and associated symptoms [7,8]. A single specific and identifiable event can cause acute traumatic 
injuries, while subacute and overuse injuries can occur without evidence of a single identifiable event due to repeated micro-trauma [6]. A recurrent injury is the repetition of the same injury[9]. It has been reported that a previous history of injury is a strong risk factor for recurrent injury $[7,10]$.

It has been found that the majority of sports injuries are sport-specific and varied on the level of participation[11]. Researches on sports injuries focus primarily on specific games or sports or specific types of injury. None of them had tried to explore the injury patterns of games and sports altogether. Therefore, in the current study, the researcher intends to explore the injury patterns of sportspersons over different types of games and sports. The results of the study can be considered as adding on with the existing researches in the field of sports injury and will help to identify the injury pattern of sportspersons of different games and sports.

\section{Materials and Methods}

\subsection{Participants}

The injury occurrences of the subjects were observed between the academic sessions of 2008 to 2017 of Lakshmibai National Institute of Physical Education (LNIPE), Gwalior, India. Total of 1008 injury cases were recorded during this time period. The record contains 649 male and 369 female injury cases. The mean age of male cases was $21.07 \pm 2.78$ and mean age of female cases was 20.81 \pm 3.01. Reported injuries at Health and Physiotherapy Centre of the institute are registered in a registry book along with the student's name, age, class of study, sport or game and injury detail. The injury reported students are issued with a health card which also contains all details about his injury. The registry is maintained by the in-charge of the physiotherapy centre. The researcher used this registry and health cards as the source of data for the study. The study was a part of $\mathrm{PhD}$ research and it was approved by the research approval committee of the institute. Data were cross verified by the researcher before the implementation of the statistical tests.

\subsection{Variables}

Age and gender were selected as variable to obtain simple demographic data about the subjects. Year of injury was used as a variable to obtain time-series data of the injuries. Total of sixteen $(\mathrm{N}=16)$ games or sports were categorised under the variable games and sports for the analysis purposes. The variable 'Body Site of Injury' was categorised into head \& neck, upper limb, trunk and lower limb (Table 1), ‘Types of Injury’ was categorised into acute, subacute and overuse injury (Table 2). 'Recurring of Injury' was also selected as a variable for the study and it was recorded with the responses yes and no.

Table 1. Injury classification according to body site of injury

\begin{tabular}{ll}
\hline Injury Type & Body Region \\
\hline Head and neck & Head, face, neck and cervical spine \\
Upper limb & $\begin{array}{l}\text { Shoulder, clavicle, upper arm, elbow, } \\
\text { forearm, wrist, hand and fingers }\end{array}$ \\
Trunk & $\begin{array}{l}\text { Sternum, ribs, upper back, abdomen, lower } \\
\text { back, pelvis and sacrum }\end{array}$ \\
Lower limb & $\begin{array}{l}\text { Hip, groin, thigh, knee, lower leg, achilles } \\
\text { tendon, ankle, foot and toe }\end{array}$ \\
\hline
\end{tabular}

Table 2. Injury classification according to sign and symptoms

\begin{tabular}{ll}
\hline Injury Type & Example \\
\hline Acute & Contusions, sprains tears etc. \\
Subacute & $\begin{array}{l}\text { Jumper's knee, tennis elbow, thrower's } \\
\text { shoulder etc. }\end{array}$ \\
Overuse & Low back pain, spondylolysis etc. \\
\hline
\end{tabular}

\subsection{Statistical Analysis}

Data were analysed using IBM SPSS software (Version 25). Simple descriptive statistics, bar and pie diagrams were used to explain the patterns of injury among sportspersons. Crosstabs function under descriptive statistics in SPSS was used to calculate statistics of different combinations.

\section{Results}

A total of 1008 injury cases were documented during the academic sessions of 2008 to 2017. Maximum (118) number of injuries were recorded in the year 2016 and minimum (82) was recorded in the year 2009 (Table 4, Figure 1). The average documented injuries were $101.80 \pm 12.59$ per year (Table 3). Out of 1008 documented injuries, $19.5 \%$ injuries occurred to football players, making it the highest among all types of games and sports. This was followed by athletics with $11.3 \%$ injuries. The third highest injuries occurred to basketball players with $10.1 \%$ of documented injuries. From overall injuries, 8.6\% of injuries occurred to cricket players followed by volleyball players (7.6\%) and hockey players (6.4\%). The handball and kabaddi players were representing $5.9 \%$ and $5.7 \%$ of overall injuries respectively. The occurrences of injuries to badminton players were $5.3 \%$. The injury percentage of other games and sports was less than five percent of total documented injuries. Among them the table tennis players were having the lowest percentage of documented injuries with only $0.9 \%$ of overall cases (Table 4).

Table 3. Descriptive statistics of year-wise documented injury

\begin{tabular}{cccc}
\hline Minimum & Maximum & Mean & Std. Deviation \\
\hline 82 & 118 & 101.80 & 12.59 \\
\hline
\end{tabular}


Table 4. Distribution of documented injuries by types of games and sports

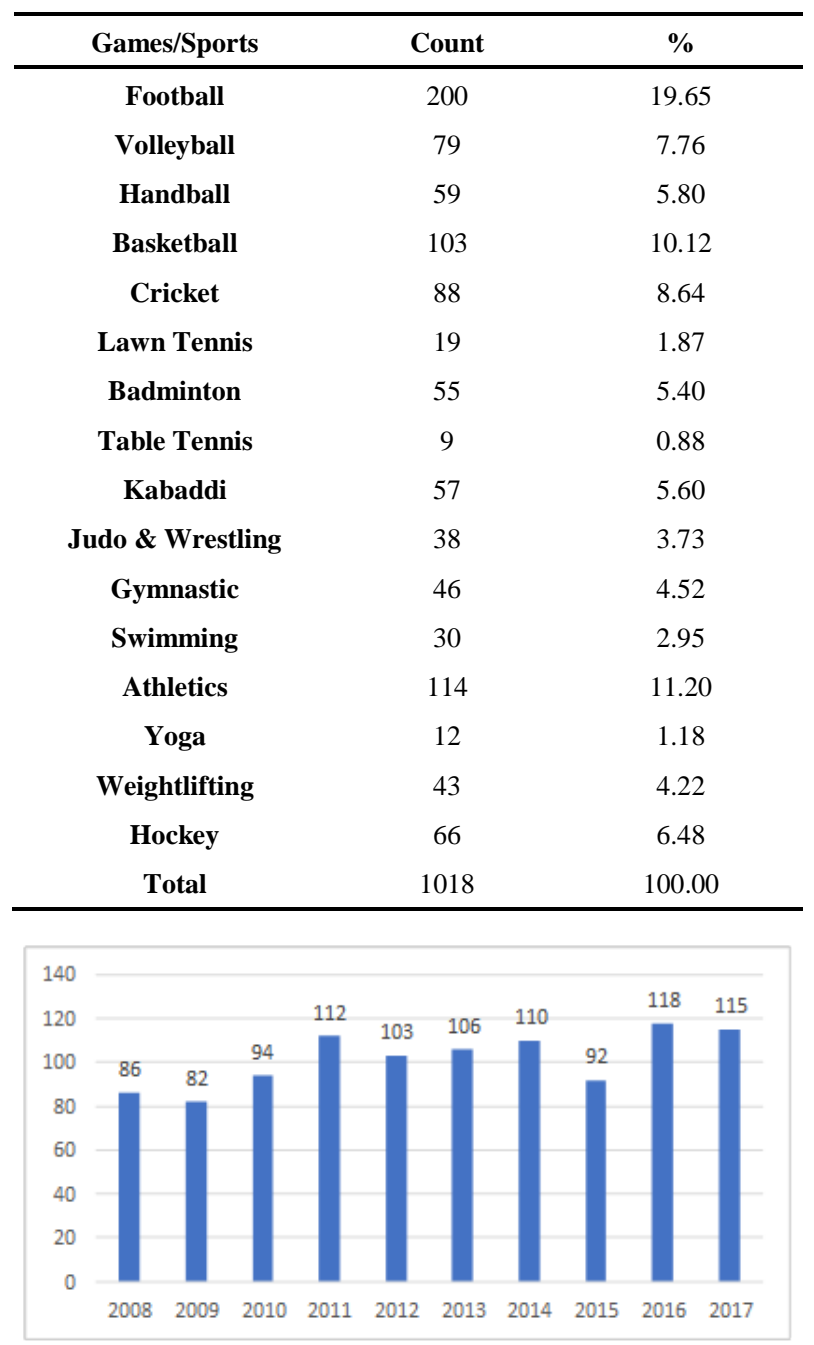

Figure 1. Number of documented injuries by year of injury (2008-2017)

Out of all recorded injury cases, 63.75\% of injuries occurred to male players, whereas female accounted for $36.25 \%$ of total injuries (Figure 2).

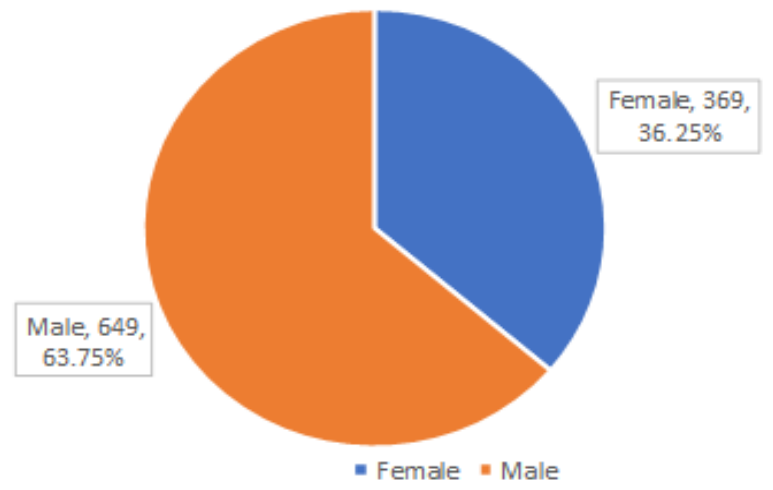

Figure 2. Distribution of documented injuries by gender

Lower limb injuries were reported as the most common injury site among sportspersons with $45.28 \%$ reported injuries followed by upper limb (29.47\%) and trunk
(20.24\%). The head and neck region were found to be the least common injury site with only $5.01 \%$ of documents injuries (Figure 3).

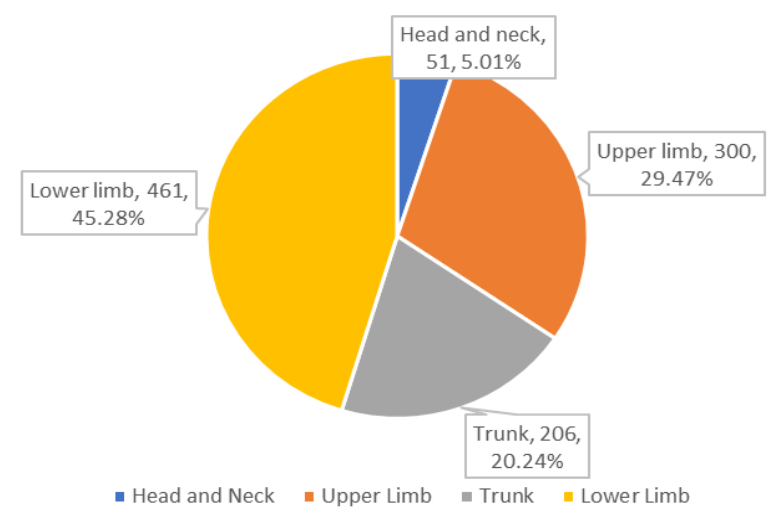

Figure 3. Distribution of documented injuries by the site of injury

Type wise distribution of injuries shows that $50.39 \%$ of overall injuries were acute in nature whereas $29.86 \%$ were overuse injury. It was also found that $19.74 \%$ of overall injuries were subacute injury (Figure 4).

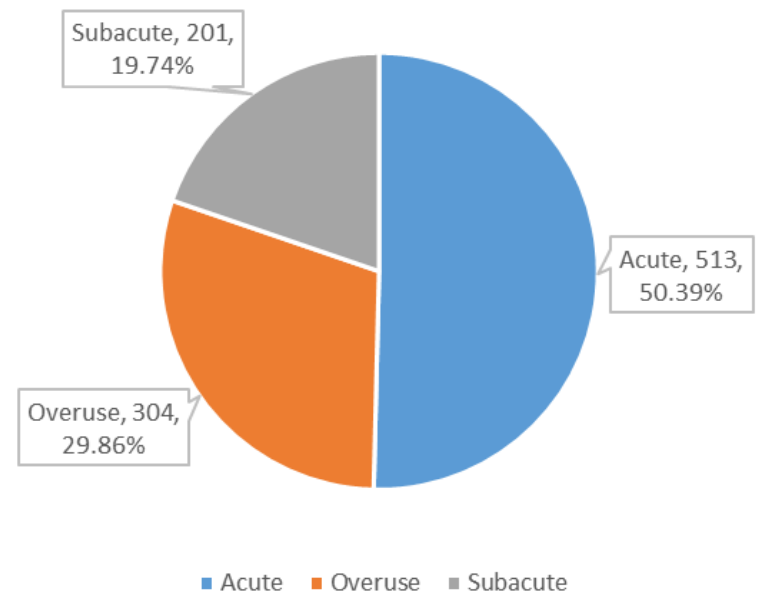

Figure 4. Distribution of documented injuries by types of injury

Analysis of injury recurrence revealed that $36.35 \%$ of documented injuries were recurrence of previous injuries whereas $63.65 \%$ of injuries were fresh in nature (Figure 5).

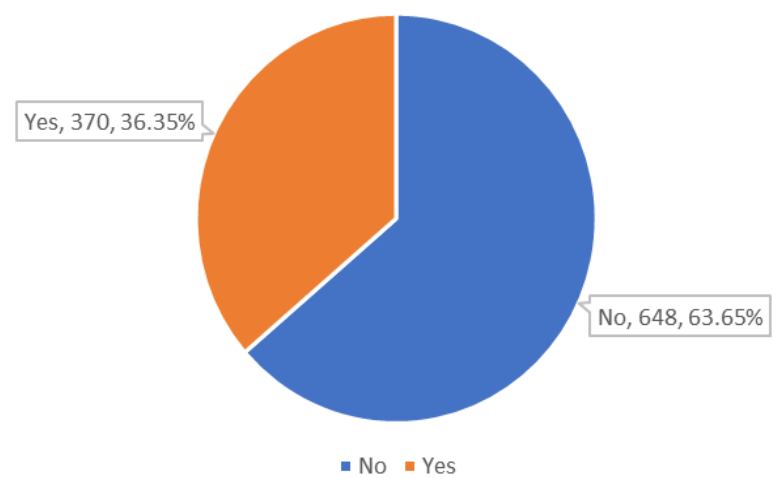

Figure 5. Distribution of documented injuries by recurrence 
Descriptive statistics of documented injuries by types of games and sports reveals the average number of injuries of different games and sports per year. The highest counts of average injury were found among the football players $(20.00 \pm 3.68)$ followed by athletics $(11.40 \pm 1.78)$ and the basketball $(10.30 \pm 2.21)$ players. The lowest counts of average injury were found in the table tennis $(1.80 \pm 0.84)$ sport followed by lawn tennis $(2.11 \pm 0.60)$ and yoga (2.40 \pm 1.14$)$. Among other games and sports, average injury counts of cricket players were $8.80 \pm 1.81$, volleyball players were $7.90 \pm 1.66$, hockey players were $6.60 \pm 1.50$, handball players were $5.90 \pm 1.45$, kabaddi players were $5.70 \pm 1.06$, badminton players were $5.50 \pm 2.17$, gymnastic players were $4.60 \pm 0.97$, weight lifting players were
$4.30 \pm 0.82$, judo and wrestling players were $3.80 \pm 1.23$ and swimming players were $3.33 \pm 1.00$ (Table 5 ).

Table 6 displays the distribution of documented injuries by year and gender. It is revealed, in all the years the maximum percentage of injury occurred to male players. The results of descriptive statistics of the percentage of gender-wise documented injuries per year reveal that throughout the decade the range of percentage of male injury was between 58.70 to 67.86 percentage and the range of percentage of female injury was between 32.14 to 41.30 percentage (Table 6). Further, it was also revealed that average $63.86 \pm 3.39 \%$ injuries occurred to male players whereas $36.14 \pm 3.39 \%$ injuries occurred to female players (Table 7).

Table 5. Descriptive statistics of documented injuries by types of games and sports

\begin{tabular}{cccccc}
\hline Games/Sports & N & Minimum & Maximum & Mean & Std. Deviation \\
\hline Football & 10 & 14 & 27 & 20.00 & 3.68 \\
Volleyball & 10 & 5 & 11 & 7.90 & 1.66 \\
Handball & 10 & 4 & 8 & 5.90 & 1.45 \\
Basketball & 10 & 7 & 14 & 10.30 & 2.21 \\
Cricket & 10 & 6 & 12 & 8.80 & 1.81 \\
Lawn Tennis & 9 & 1 & 3 & 2.11 & 0.60 \\
Table Tennis & 5 & 1 & 3 & 1.80 & 0.84 \\
Badminton & 10 & 2 & 9 & 5.50 & 2.17 \\
Kabaddi & 10 & 4 & 7 & 3.80 & 1.06 \\
Judo and Wrestling & 10 & 2 & 7 & 4.60 & 1.23 \\
Gymnastic & 10 & 4 & 5.33 & 0.97 \\
Swimming & 9 & 2 & 14 & 11.40 & 1.00 \\
Athletics & 10 & 9 & 4 & 2.40 & 1.78 \\
Yoga & 5 & 1 & 6 & 4.30 & 1.14 \\
Weightlifting & 10 & 3 & 9 & 6.60 & 0.82 \\
Hockey & 10 & 4 & & 1.51 \\
\hline
\end{tabular}

Table 6. Distribution of documented injuries by year and gender

\begin{tabular}{ccccc}
\hline \multirow{2}{*}{ Year } & \multicolumn{3}{c}{ Gender of the subject } \\
\cline { 2 - 5 } & Female & \% & Male & \% \\
\hline $\mathbf{2 0 0 8}$ & 28 & 32.56 & 58 & 67.44 \\
$\mathbf{2 0 0 9}$ & 29 & 35.37 & 53 & 64.63 \\
$\mathbf{2 0 1 0}$ & 31 & 32.98 & 63 & 67.02 \\
$\mathbf{2 0 1 1}$ & 36 & 32.14 & 76 & 67.86 \\
$\mathbf{2 0 1 2}$ & 34 & 33.01 & 69 & 66.99 \\
$\mathbf{2 0 1 3}$ & 39 & 36.79 & 67 & 63.21 \\
$\mathbf{2 0 1 4}$ & 44 & 40.00 & 66 & 60.00 \\
$\mathbf{2 0 1 5}$ & 38 & 41.30 & 54 & 58.70 \\
$\mathbf{2 0 1 6}$ & 46 & 38.98 & 72 & 61.02 \\
$\mathbf{2 0 1 7}$ & 44 & 38.26 & 71 & 61.74 \\
\hline
\end{tabular}

Table 7. Descriptive statistics of the percentage of gender-wise documented injuries per year

\begin{tabular}{ccccc}
\hline Gender & Minimum & Maximum & Mean & Std. Deviation \\
\hline Male & 58.70 & 67.86 & 63.86 & 3.39 \\
Female & 32.14 & 41.30 & 36.14 & 3.39 \\
\hline
\end{tabular}


Table 8 displays the documented injuries by year and body site of injury. It reveals that in the whole decade, lower limb area suffered from the maximum percentage of injuries followed by upper limb area (except the year 2009). It was also found that the trunk area suffered from third-highest percentage of injuries and the head and neck area was the lowest sufferer of injuries in the whole decade. Further, the descriptive statistics of the percentage of body sites of documented injuries per year reveals that the head and neck area suffered from average $5 \pm 1.76 \%$ of total injuries per year. The upper limb area suffers from
$29.2 \pm 3.38 \%$ of total injuries per year whereas the trunk area suffers from $20.37 \pm 2.41 \%$ of total injuries per year. And the lower limb area suffers from $45.43 \pm 2.84 \%$ of total injuries per year (Table 9).

Distribution of injuries by year and recurring of injury reveals that most of the injuries were non-recurring in nature (Table 10). Further, the descriptive statistics of the percentages of recurring of injury reveals that average $64.07 \pm 6.62$ percentage of injuries were non-recurring whereas average $35.93 \pm 6.62$ percentage of injuries were recurring in nature (Table 11).

Table 8. Distribution of documented injuries by year and body site of injury

\begin{tabular}{ccccccccc}
\hline \multirow{2}{*}{ Year } & \multicolumn{10}{c}{ Body Site of Injury } \\
\cline { 2 - 9 } & Head and Neck & $\mathbf{\%}$ & Upper Limb & \% & Trunk & \% & Lower Limb & \% \\
\hline $\mathbf{2 0 0 8}$ & 4 & 4.65 & 22 & 25.58 & 16 & 18.60 & 44 & 51.16 \\
$\mathbf{2 0 0 9}$ & 5 & 6.10 & 19 & 23.17 & 20 & 24.39 & 38 & 46.34 \\
$\mathbf{2 0 1 0}$ & 2 & 2.13 & 29 & 30.85 & 19 & 20.21 & 44 & 46.81 \\
$\mathbf{2 0 1 1}$ & 4 & 3.57 & 33 & 29.46 & 24 & 21.43 & 51 & 45.54 \\
$\mathbf{2 0 1 2}$ & 9 & 8.74 & 30 & 29.13 & 23 & 22.33 & 41 & 39.81 \\
$\mathbf{2 0 1 3}$ & 6 & 5.66 & 35 & 33.02 & 19 & 17.92 & 46 & 43.40 \\
$\mathbf{2 0 1 4}$ & 5 & 4.55 & 33 & 30.00 & 22 & 20.00 & 50 & 45.45 \\
$\mathbf{2 0 1 5}$ & 4 & 4.35 & 25 & 27.17 & 21 & 22.83 & 42 & 45.65 \\
$\mathbf{2 0 1 6}$ & 7 & 5.93 & 34 & 28.81 & 23 & 19.49 & 54 & 45.76 \\
$\mathbf{2 0 1 7}$ & 5 & 4.35 & 40 & 34.78 & 19 & 16.52 & 51 & 44.35 \\
\hline
\end{tabular}

Table 9. Descriptive statistics of the percentage of body sites of documented injuries per year

\begin{tabular}{ccccc}
\hline Body Site of Injury & Minimum & Maximum & Mean & Std. Deviation \\
\hline Head and Neck & 2.13 & 8.74 & 5.00 & 1.76 \\
Upper Limb & 23.17 & 34.78 & 29.20 & 3.38 \\
Trunk & 16.52 & 24.39 & 20.37 & 2.41 \\
Lower Limb & 39.81 & 51.16 & 45.43 & 2.84 \\
\hline
\end{tabular}

Table 10. Distribution of documented injuries by year and recurring of Injury

\begin{tabular}{lllll}
\hline \multirow{2}{*}{ year } & \multicolumn{3}{c}{ Recurring of Injury } \\
\cline { 2 - 5 } & $\mathbf{N o}$ & $\mathbf{\%}$ & Yes & \% \\
\hline $\mathbf{2 0 0 8}$ & 68 & 79.07 & 18 & 20.93 \\
$\mathbf{2 0 0 9}$ & 52 & 63.41 & 30 & 36.59 \\
$\mathbf{2 0 1 0}$ & 68 & 72.34 & 26 & 27.66 \\
$\mathbf{2 0 1 1}$ & 70 & 62.50 & 42 & 37.50 \\
$\mathbf{2 0 1 2}$ & 63 & 61.17 & 40 & 38.83 \\
$\mathbf{2 0 1 3}$ & 62 & 58.49 & 44 & 41.51 \\
$\mathbf{2 0 1 4}$ & 69 & 62.73 & 41 & 37.27 \\
$\mathbf{2 0 1 5}$ & 56 & 60.87 & 36 & 39.13 \\
$\mathbf{2 0 1 6}$ & 74 & 62.71 & 44 & 37.29 \\
$\mathbf{2 0 1 7}$ & 66 & 57.39 & 49 & 42.61 \\
\hline
\end{tabular}

Table 11. Descriptive statistics of the percentage of recurring of injuries per year

\begin{tabular}{ccccc}
\hline Recurring of Injury & Minimum & Maximum & Mean & Std. Deviation \\
\hline Yes & 57.39 & 79.07 & 64.07 & 6.62 \\
No & 20.93 & 42.61 & 35.93 & 6.62 \\
\hline
\end{tabular}


Table 12 displays the documented injuries by year and type of injury. It is seen that in all the years, most of the injury occurrences were acute in nature followed by overuse and subacute recurrent injuries (except the year 2012). Further, the descriptive statistics of the percentage of the type of injury per year displays that the average percentage of occurrence of acute injuries per year was $50.52 \pm 3.33$, the average percentage of occurrence of overuse injuries per year was $29.90 \pm 5.16$ whereas the average percentage of occurrence of subacute recurrent injuries per year was $19.57 \pm 3.45$ (Table 13 ).

The distribution of documented injuries by type of games and sports and gender of the subjects reveals that, except in gymnastic, swimming and yoga, in most of the other games and sports, the maximum percentage of injuries occurred to male players (Table 14).

Table 12. Distribution of documented injuries by year and type of injury

\begin{tabular}{ccccccc}
\hline \multirow{2}{*}{ Year } & \multicolumn{7}{c}{ Type of Injury } \\
\cline { 2 - 7 } & Acute & \% & Overuse & \% & Subacute & \% \\
\hline $\mathbf{2 0 0 8}$ & 45 & 52.33 & 25 & 29.07 & 16 & 18.60 \\
$\mathbf{2 0 0 9}$ & 44 & 53.66 & 27 & 32.93 & 11 & 13.41 \\
$\mathbf{2 0 1 0}$ & 48 & 51.06 & 27 & 28.72 & 19 & 20.21 \\
$\mathbf{2 0 1 1}$ & 60 & 53.57 & 30 & 26.79 & 22 & 19.64 \\
$\mathbf{2 0 1 2}$ & 55 & 53.40 & 23 & 22.33 & 25 & 24.27 \\
$\mathbf{2 0 1 3}$ & 46 & 43.40 & 44 & 41.51 & 20 & 16.09 \\
$\mathbf{2 0 1 4}$ & 53 & 48.18 & 26 & 28.64 & 20 & 18.18 \\
$\mathbf{2 0 1 5}$ & 46 & 50.00 & 34 & 28.81 & 28 & 21.74 \\
$\mathbf{2 0 1 6}$ & 56 & 47.46 & 31 & 26.96 & 24 & 23.73 \\
$\mathbf{2 0 1 7}$ & 60 & 52.17 & & & 20.87 \\
\hline
\end{tabular}

Table 13. Descriptive statistics of the percentage of the type of injury per year

\begin{tabular}{ccccc}
\hline Type of Injury & Minimum & Maximum & Mean & Std. Deviation \\
\hline Acute & 43.40 & 53.66 & 50.52 & 3.33 \\
Overuse & 22.33 & 41.51 & 29.90 & 5.16 \\
Subacute recurrent & 13.41 & 24.27 & 19.57 & 3.45 \\
\hline
\end{tabular}

Table 14. Distribution of documented injuries by types of games and sports and gender

\begin{tabular}{|c|c|c|c|c|}
\hline \multirow{2}{*}{ Games/Sports } & \multicolumn{4}{|c|}{ Gender } \\
\hline & Female & $\%$ & Male & $\%$ \\
\hline Football & 45 & 22.50 & 155 & 77.50 \\
\hline Volleyball & 34 & 43.04 & 45 & 56.96 \\
\hline Handball & 14 & 23.73 & 45 & 76.27 \\
\hline Basketball & 47 & 45.63 & 56 & 54.37 \\
\hline Cricket & 14 & 15.91 & 74 & 84.09 \\
\hline Lawn Tennis & 5 & 26.32 & 14 & 73.68 \\
\hline Badminton & 22 & 40.00 & 33 & 60.00 \\
\hline Table Tennis & 3 & 33.33 & 6 & 66.67 \\
\hline Kabaddi & 21 & 36.84 & 36 & 63.16 \\
\hline Judo \& Wrestling & 11 & 28.95 & 27 & 71.05 \\
\hline Gymnastic & 32 & 69.57 & 14 & 30.43 \\
\hline Swimming & 18 & 60.00 & 12 & 40.00 \\
\hline Athletics & 45 & 39.47 & 69 & 60.53 \\
\hline Yoga & 10 & 83.33 & 2 & 16.67 \\
\hline Weightlifting & 16 & 37.21 & 27 & 62.79 \\
\hline Hockey & 32 & 48.48 & 34 & 51.52 \\
\hline
\end{tabular}


The table displaying the distribution of injury occurrences of different games and sports by different body sites of injury reveals that in sports like football, basketball, kabaddi, gymnastic, athletics and weightlifting; the maximum percentage of injuries occurred to lower limb area. On the other hand, in sports like; volleyball, handball, judo and wrestling, cricket, lawn tennis, badminton, table tennis and swimming; the maximum percentage of injuries occurred to the upper limb area. In sports like yoga and hockey maximum percentage of injuries occurred to the trunk area. Except in football and yoga, among all other selected games and sports head and neck area was found to be the least injured area of injury (Table 15).

The table 16 displays games and sports-wise recurring of injury. The results reveal that only in judo \& wrestling, badminton and gymnastic; recurrence of injuries was higher than non-recurrence. Further, it is also revealed that in the sport badminton, the highest number of injury recurrences has occurred.

Table 15. Distribution of documented injuries by types of games and sports and body site of injury

\begin{tabular}{|c|c|c|c|c|}
\hline \multirow{2}{*}{ Games/Sports } & \multicolumn{4}{|c|}{ Body Site of Injury } \\
\hline & Head and Neck & Upper Limb & Trunk & Lower Limb \\
\hline Football & $36(18 \%)$ & 7 (3.50\%) & $23(11.50 \%)$ & 134 (67\%) \\
\hline Volleyball & $0(0 \%)$ & 43 (54.43\%) & $18(22.78)$ & $18(22.78)$ \\
\hline Handball & $0(0 \%)$ & 38 (64.41\%) & 10 (16.95\%) & $11(18.64 \%)$ \\
\hline Basketball & $5(4.85 \%)$ & 10 (9.71\%) & 12 (11.65\%) & 76 (73.79) \\
\hline Cricket & $0(0 \%)$ & 52 (59.09\%) & 18 (20.45\%) & 18 (20.45\%) \\
\hline Lawn Tennis & $0(0 \%)$ & 17 (89.47\%) & $0(0 \%)$ & $2(10.53 \%)$ \\
\hline Badminton & $0(0 \%)$ & $33(60 \%)$ & $10(18.18 \%)$ & $12(21.82 \%)$ \\
\hline Table Tennis & $0(0 \%)$ & 7 (77.78\%) & $1(11.11 \%)$ & $1(11.11 \%)$ \\
\hline Kabaddi & $1(1.75 \%)$ & $6(10.53 \%)$ & $2(3.51 \%)$ & 48 (84.21\%) \\
\hline Judo \& Wrestling & $1(2.63 \%)$ & $24(63.16 \%)$ & 8 (21.05\%) & $5(13.16 \%)$ \\
\hline Gymnastic & $5(10.87 \%)$ & $14(30.43 \%)$ & $6(13.04 \%)$ & $21(45.65 \%)$ \\
\hline Swimming & $0(0 \%)$ & 17 (56.67\%) & $11(36.67 \%)$ & $2(6.67 \%)$ \\
\hline Athletics & $0(0 \%)$ & $21(18.42 \%)$ & $21(18.42 \%)$ & $72(63.16 \%)$ \\
\hline Yoga & $3(25 \%)$ & $2(16.67 \%$ & 7 (58.33\%) & $0(0 \%)$ \\
\hline Weightlifting & $0(0 \%)$ & 3 (6.98\% & 19 (44.19\%) & $21(48.84 \%)$ \\
\hline Hockey & $0(0 \%)$ & $6(9.09 \%)$ & 40 (60.61\%) & $20(30.30 \%)$ \\
\hline
\end{tabular}

Table 16. Distribution of documented injuries by types of games and sports and recurring of injury

\begin{tabular}{|c|c|c|c|c|}
\hline \multirow{2}{*}{ Games/Sports } & \multicolumn{4}{|c|}{ Recurring of Injury } \\
\hline & No & $\%$ & Yes & $\%$ \\
\hline Football & 142 & 71.00 & 58 & 29.00 \\
\hline Volleyball & 40 & 50.63 & 39 & 49.37 \\
\hline Handball & 38 & 64.41 & 21 & 35.59 \\
\hline Basketball & 63 & 61.17 & 40 & 38.83 \\
\hline Cricket & 52 & 59.09 & 36 & 40.91 \\
\hline Lawn Tennis & 14 & 73.68 & 5 & 26.32 \\
\hline Badminton & 24 & 43.64 & 31 & 56.36 \\
\hline Table Tennis & 9 & 100.00 & 0 & 0.00 \\
\hline Kabaddi & 55 & 96.49 & 2 & 3.51 \\
\hline Judo \& Wrestling & 17 & 44.74 & 21 & 55.26 \\
\hline Gymnastic & 23 & 50.00 & 23 & 50.00 \\
\hline Swimming & 26 & 86.67 & 4 & 13.33 \\
\hline Athletics & 69 & 60.53 & 45 & 39.47 \\
\hline Yoga & 11 & 91.67 & 1 & 8.33 \\
\hline Weightlifting & 31 & 72.09 & 12 & 27.91 \\
\hline Hockey & 34 & 51.52 & 32 & 48.48 \\
\hline
\end{tabular}


Table 17 displays the distribution of injuries by type of games and sports and type of injuries. The results reveal that, in most of the games and sports, the maximum percentage of injuries were acute in nature except in lawn tennis, badminton, table tennis, swimming and hockey in which overuse type of injury percentage was higher.

Table 18 reveals the distribution of documented injures by gender and site of injury. For both male and female maximum percentage of injury occurred to lower limb area of the body (Male: $43.61 \%$, Female: $48.24 \%$ ) whereas the lowest percentage of injury occurred to the head and neck area (Male: 5.08\%, Female: $4.88 \%$ ). For both the genders, almost $20 \%$ of overall injuries occurred to the trunk area (Male: 20.18\%, Female:
20.33\%). For male $31.12 \%$ injury occurred to the shoulder area and for female, it was $26.56 \%$.

Table 19 displays the documented injuries by gender and recurring of injury. It reveals that for both the genders almost 35\% (Male: 36.88\%, Female: 35.14\%) of total injuries were recurring whereas 65\% (Male: 63.12\%; Female: $64.86 \%$ ) of total injuries were not recurring.

Table 20 displays the documented injuries by gender and type of injuries. The result reveals that among all-female injuries $50.14 \%$ were acute in nature, $31.71 \%$ were overuse and $18.16 \%$ were subacute injuries. In male $50.54 \%$ of overall injuries were acute, $28.81 \%$ were overuse and $20.65 \%$ of overall injuries were subacute.

Table 17. Distribution of documented injuries by types of games and sports and types of injury

\begin{tabular}{ccccccc}
\hline \multirow{2}{*}{ Games/Sports } & \multicolumn{5}{c}{ Type of Injury } \\
\cline { 2 - 7 } & Acute & \% & Overuse & \% & Subacute & \% \\
\hline Football & 115 & 57.50 & 48 & 24.00 & 37 & 18.50 \\
Volleyball & 33 & 41.77 & 27 & 34.18 & 19 & 24.05 \\
Handball & 24 & 40.68 & 21 & 35.59 & 14 & 23.73 \\
Basketball & 51 & 49.51 & 28 & 27.18 & 24 & 23.30 \\
Cricket & 39 & 44.32 & 29 & 32.95 & 20 & 22.73 \\
Lawn Tennis & 7 & 36.84 & 9 & 47.37 & 3 & 15.79 \\
Badminton & 16 & 29.09 & 21 & 38.18 & 18 & 32.73 \\
Table Tennis & 1 & 11.11 & 6 & 66.67 & 2 & 22.22 \\
Kabaddi & 56 & 98.25 & 0 & 0.00 & 1 & 1.75 \\
Judo \& Wrestling & 17 & 44.74 & 10 & 26.32 & 11 & 28.95 \\
Gymnastic & 27 & 58.70 & 14 & 30.43 & 5 & 10.87 \\
Swimming & 9 & 30.00 & 14 & 46.67 & 7 & 23.33 \\
Athletics & 52 & 45.61 & 39 & 34.21 & 23 & 20.18 \\
Yoga & 8 & 66.67 & 0 & 0.00 & 4 & 33.33 \\
Weightlifting & 33 & 76.74 & 6 & 13.95 & 4 & 9.30 \\
Hockey & 25 & 37.88 & 32 & 48.48 & 9 & 13.64 \\
\hline
\end{tabular}

Table 18. Distribution of documented injuries by gender and site of injury

\begin{tabular}{cccccccccc}
\hline \multirow{2}{*}{ Gender } & \multicolumn{10}{c}{ Site of injury } \\
\cline { 2 - 10 } & $\begin{array}{c}\text { Head and } \\
\text { Neck }\end{array}$ & $\mathbf{\%}$ & $\begin{array}{c}\text { Upper } \\
\text { Limb }\end{array}$ & \% & Trunk & \% & Lower Limb & \% \\
\hline Female & 18 & 4.88 & 98 & 26.56 & 75 & 20.33 & 178 & 48.24 \\
Male & 33 & 5.08 & 202 & 31.12 & 131 & 20.18 & 283 & 43.61 \\
\hline
\end{tabular}

Table 19. Distribution of documented injuries by gender and recurring of injury

\begin{tabular}{ccccc}
\hline \multirow{2}{*}{ Recurring of Injury } & \multicolumn{4}{c}{ Gender of the subject } \\
\cline { 2 - 5 } & Female & \% & Male & \% \\
\hline No & 239 & 36.88 & 409 & 63.12 \\
Yes & 130 & 35.14 & 240 & 64.86 \\
\hline
\end{tabular}

Table 20. Distribution of documented injuries by gender and type of injury

\begin{tabular}{ccccccc}
\hline \multirow{2}{*}{ Gender } & \multicolumn{7}{c}{ Type of injury } \\
\cline { 2 - 7 } & Acute & \% & Overuse & \% & Subacute & \% \\
\hline Female & 185 & 50.14 & 117 & 31.71 & 67 & 18.16 \\
Male & 328 & 50.54 & 187 & 28.81 & 134 & 20.65 \\
\hline
\end{tabular}


Table 21. Distribution of documented injuries by the site of injury and recurring of injury

\begin{tabular}{ccccc}
\hline & \multicolumn{5}{c}{ Recurring of injury } \\
\cline { 2 - 5 } & No & \% & Yes & \% \\
\hline Head and Neck & 48 & 94.12 & 3 & 5.88 \\
Upper Limb & 181 & 60.33 & 119 & 39.67 \\
Trunk & 122 & 59.22 & 84 & 40.78 \\
Lower Limb & 297 & 64.43 & 164 & 35.57 \\
\hline
\end{tabular}

Table 22. Distribution of documented injuries by body site of injury and type of injury

\begin{tabular}{ccccccc}
\hline & & & \multicolumn{3}{c}{ Type of Injury } \\
\cline { 2 - 7 } & Acute & \% & Overuse & \% & Subacute & \% \\
\hline Head and neck & 48 & 94.12 & 3 & 5.88 & 0 & 0.00 \\
Upper limb & 132 & 44.00 & 83 & 27.67 & 85 & 28.33 \\
Trunk & 82 & 39.81 & 87 & 42.23 & 37 & 17.96 \\
Lower Limb & 251 & 54.45 & 131 & 28.42 & 79 & 17.14 \\
\hline
\end{tabular}

Table 23. Distribution of documented injuries by type of injury and site of injury

\begin{tabular}{ccccccccc}
\hline & \multicolumn{1}{c}{ Site of injury } \\
\cline { 2 - 9 } & $\begin{array}{c}\text { Head and } \\
\text { Neck }\end{array}$ & $\mathbf{\%}$ & Upper Limb & $\mathbf{\%}$ & Trunk & $\mathbf{\%}$ & $\begin{array}{c}\text { Lower } \\
\text { Limb }\end{array}$ & \% \\
\hline Acute & 48 & 9.36 & 132 & 25.73 & 82 & 15.98 & 251 & 48.93 \\
Overuse & 3 & 0.99 & 83 & 27.30 & 87 & 28.62 & 131 & 43.09 \\
Subacute & 0 & 0 & 85 & 42.29 & 37 & 18.41 & 79 & 39.30 \\
\hline
\end{tabular}

Table 24. Distribution of documented injuries by type of injury and recurrence

\begin{tabular}{ccccc}
\hline & \multicolumn{4}{c}{ Recurrence of injury } \\
\cline { 2 - 5 } & No & \% & Yes & \% \\
\hline Acute & 402 & 78.36 & 111 & 21.64 \\
Overuse & 140 & 46.05 & 164 & 53.95 \\
Subacute & 106 & 52.74 & 95 & 47.26 \\
\hline
\end{tabular}

Table 25. Distribution of documented injuries by recurrence and type of injury

\begin{tabular}{ccccccc}
\hline & \multicolumn{7}{c}{ Type of injury } \\
\cline { 2 - 7 } & Acute & \% & Overuse & \% & Subacute & \% \\
\hline No & 402 & 62.04 & 140 & 21.60 & 106 & 16.36 \\
Yes & 111 & 30.00 & 164 & 44.32 & 95 & 25.68 \\
\hline
\end{tabular}

Table 21 displays the distribution of documented injuries by the site of injury and recurring of injury. It is revealed that among all head and neck region injuries, $94.12 \%$ were non-recurring in nature whereas only $5.88 \%$ were the recurring injuries.

Among all upper limb injuries, 60.33\% were non-recurring injuries whereas $39.67 \%$ were recurring. In the trunk region, $59.22 \%$ injuries were non-recurring whereas $40.78 \%$ were the recurring injuries. In the lower limb region, $64.43 \%$ injuries were non-recurring whereas $35.57 \%$ were recurring in nature.

From table 22 it can be understood that among Head and neck injuries $94.12 \%$ were acute in nature whereas $5.88 \%$ were overuse injuries. Total upper limb injury consisted of
$44 \%$ acute, $27.67 \%$ overuse and $28.33 \%$ subacute injuries. On the other hand, $39.81 \%$ of trunk injury were acute, $42.23 \%$ were overuse and $17.96 \%$ were the subacute injuries. In the lower limb region, $54.45 \%$ injuries were acute, $28.42 \%$ were overuse and $17.14 \%$ were the subacute injuries.

Table 23 displays the distribution of injuries by type and site of injury. It can be seen, $9.36 \%$ of acute injury occurred to the head and neck region, $25.73 \%$ occurred to the upper limb, $15.98 \%$ occurred to the trunk and $48.93 \%$ occurred to the lower limb region. Among overuse injuries, 0.99\% occurred to the head and neck region, $27.30 \%$ occurred to the upper limb region, $28.62 \%$ occurred to the trunk region and $43.09 \%$ occurred to the lower limb region. On the other 
hand, $42.29 \%$ of subacute injury occurred to the upper limb region, $18.41 \%$ occurred to the trunk and $39.30 \%$ occurred to the lower limb region.

Table 24 shows that $78.36 \%$ of the acute injuries were non-recurrent and $21.64 \%$ were the recurrent injuries, $46.05 \%$ of the overuse injuries were non-recurrent and $53.95 \%$ were recurrent and among the subacute injuries $52.74 \%$ were non-recurrent and $47.26 \%$ were the recurrent injuries. Further, table 24 reveals that $62.04 \%$ of non-recurrent injuries were acute, $21.60 \%$ were overuse and $16.36 \%$ were subacute injuries. Among recurrent injuries, $30 \%$ were acute, $44.32 \%$ were overuse and $25.68 \%$ were subacute injuries.

Most of the non-recurring injuries were acute (62.04\%) in nature, followed by the overuse $(21.60 \%)$ and the subacute $(16.36 \%)$ injuries. The recurring injuries were mostly overuse injuries (44.32\%) followed by the acute (30\%) and the subacute (25.68\%) injuries (Table 25).

\section{Discussion}

Injuries increase the health care costs of a young athlete. It also affects the normal life of a sports person. Sometimes it becomes a lifelong physical impairment. Therefore, researchers have been trying to identify the factors and pattern of sports injuries. Most of the time these studies are sports or games oriented and they concentrate primarily on injury pattern of that particular sport or game. In the present study, the researcher intended to understand the injury pattern of sixteen different games and sports. For that purpose, total of 1008 injury cases were analyzed.

As expected, it was revealed that maximum injuries occurred to football players (19.5\%), on the other hand, lowest injury cases were observed to table tennis players. Kerr, et al. [12] also reported footballers were estimated to have highest counts of injuries (22.4\%) among all injuries. The same study also revealed that footballer accounted for $36.3 \%$ of male injuries [12]. Study conducted by Ristolainen et al.[13] also reported that male players were at increased risk of injury compared to female players. The current study also revealed that male players recorded maximum percentage of injury compared to female players in most of the games and sports. Except in gymnastic, swimming and yoga, in all other games and sports male percentage of injury was higher than female players. Anderson [14] reported that the lower extremity is the most common anatomical area for sports injury. The result of the current study also exhibited a similar result. It exhibits that lower limb area is suffered from maximum percentage of injury (45.43 \pm 2.84$)$. Researches conducted by Welton, et al.[15] reported that only $10.5 \%$ of overall injuries were recurrent. Most of the recurrent injuries were subsequent of previous injuries. The current research also displays a similar trend. Most of the injuries were non-recurrent in nature. A single adverse incident causes acute injury whereas the overuse injuries occur over time [7]. Subacute injuries occur when the victim get injured even before recovery from the previous injury. In the current study, most injuries are found to be acute in nature followed by overuse and subacute injuries. Majority of head and neck injury occurs to the sports which involve upper extremity or head action during play [16]. In most cases death during sports is caused by head injury. The sports which demand great biomechanical involvement of shoulder may be prone to upper limb injuries. Sports like tennis, volleyball, handball, or badminton demand great amount of arm movements. These demands mean that players are more prone to arm or upper limb injuries [17]. In the current study it is found that in sports: volleyball, handball, judo and wrestling, cricket, lawn tennis, badminton, table tennis and swimming; maximum percentage of injuries occurred to upper limb area. Rodriguez et al. [18] had mentioned shoulder is the most frequently affected area of amateur badminton players. The same study also mentioned that in lower limb region knee and in upper limb region shoulder area are affected by most injuries [18]. Volleyball players are prone to shoulder injuries because of repeated involvement of overhead motions [19,20]. Myklebust had found, $19 \%$ of overall acute injuries and $15 \%$ of overall overuse injuries of volleyball players occurred to the upper limb region [21]. Review study conducted by Pocecco et al. had reported knee, shoulder and finger areas as the most frequently affected injury region [22]. Most of these injuries were result of throwing mechanism involving primarily shoulder [22]. Investigation on cricket injuries revealed that bowlers account $41.3 \%$ of total cricket injuries [23]. Young and Lydecker [24] had suggested not to involve throwing activities during practice for fast recovery from shoulder injuries. Study on epidemiology of tennis injuries revealed the most common overuse tennis injury in shoulder region whereas the lower extremity was found to be more prone to acute injuries [25]. Similar study on epidemiology of swimming had reported 91\% exhibition of shoulder injury by young swimmers [26]. Injuries in trunk area indicate the injuries occurred in back, chest and abdomen region. Back injuries generally associated with movement like repeated flexion, extension and rotation [27]. In the current study it is found that in yoga and hockey maximum percentage of injury occurred to trunk area. Lower limb area of human body is the most common injured area in sports [14,28,29]. In the current study also, lower limb is found to be the most affected area by injury. Brant et al. had reported lower extremity sports injuries are highest among football players followed by basketball whereas swimmers suffer from lowest percent of lower extremity injuries[30]. The notable findings of the current study also revealed that among all reported injuries, in badminton the number of injury recurrence was higher compared to other sports. According to Saunders et al. 34\% of injured kicking and running sports player may exhibit recurrence of hamstring injury [31]. The results of the 
current study also reveal that in most of the racket sports injuries were overuse injury. Further it is seen that both genders have a similar pattern of injury occurrence and recurrence over different sites and types of injury. It was found that almost one tenth of the all head and neck injuries were overuse injury and others were acute injury. Among upper limb injuries 44\% were acute, $28.33 \%$ were subacute and $27.67 \%$ were overuse injury. Among trunk injuries subacute injury accounted for almost one fifth of overall injuries, whereas other part was almost equally divided by acute and overuse injury. The current study reported half of the acute injuries occurred to lower limb area whereas upper limb accounted one fourth of the total injury. Among overuse injuries lower limb accounted 43.09\% of total injury whereas trunk and upper limb each accounted almost $30 \%$ of total injuries. Upper limb area suffered from maximum subacute injuries followed by lower limb and trunk. The study revealed that only one fifth of acute injuries were recurrent whereas almost halves of overuse injuries were recurrent. Subacute injures also exhibited a similar trend. Among non-recurrent injuries, maximum percentage of injuries were acute followed by overuse injury. On the other hand, overuse injuries accounted maximum recurrent injury followed by acute and subacute injuries.

\section{Conclusions}

The results of the current study have many practical implications. It gives an opportunity to investigate the patterns of injuries over different games and sports. Furthermore, during training we can consider the results of the current study to prevent sports injuries by applying preventive measures against injury pattern of particular games or sports. Knowledge of sports specific injury pattern can help coaches, physical educationist, or sports scientist to identify sports activities with high injury risk and can help them to develop targeted training methods to prevent future injuries.

The present study was subjected to some limitations. First, the institute where the research was conducted didn't have a policy to equally distribute the students to different games and sports. Therefore, varied number of participations in different games and sports might have affected the reported injury number. In some sports there were higher number of participants which increased the probability of higher injury reporting whereas less participated sports had lower injury reporting. Second, there was gender imbalance among the number of students in the institute which also affects the reported injury number. Third and finally, some students didn't prefer institute physiotherapy center for their treatment, instead they preferred outside specialist. These injury cases were not been reported and there was no way to track those cases. Therefore, the researchers were unable to include those cases in the current study. In addition to it, the current study does not address specific injuries, instead it focused primarily on the classification of injuries. Therefore, the researcher recommends to address such issues in future studies and suggests to prevent the limitations which have been mentioned earlier in the study.

\section{Acknowledgements}

The authors would like to acknowledge the support from all members of physiotherapy center of Lakshmibai National Institute of Physical Education, Gwalior.

\section{Conflict of Interest}

The authors declare that there is no conflict of interest.

\section{REFERENCES}

[1] Dhillon H., Dhillon S., Dhillon M. Current Concepts in Sports Injury Rehabilitation. Indian J Orthop 2017;51:52936. https://doi.org/10.4103/ortho.IJOrtho_226_17.

[2] Sports Injuries: Types, Treatments, and Prevention. OnHealth 2016. https://www.onhealth.com/content/1/sports _injuries (accessed April 20, 2020).

[3] Conrad M. The Business of Sports: A Primer for Journalists. 2nd ed. New York: Routledge; 2011.

[4] Kahlenberg C.A., Nair R., Monroe E., Terry M.A., Edwards S.L.. Incidence of injury based on sports participation in high school athletes. Phys Sportsmed 2016;44:269-73. https://doi.org/10.1080/00913847.2016.1180269.

[5] Sallis R.E., Jones K., Sunshine S., Smith G., Simon L. Comparing Sports Injuries in Men and Women. Int J Sports Med 2001;22:420-3. https://doi.org/10.1055/s-2001-16246.

[6] Verhagen E., Mechelen W.V.. Sports Injury Research. New York: OXFORD University Press; 2010.

[7] Knight K.L. More precise classification of orthopaedic injury types and treatment will improve patient care. J Athl Train 2008;43:117-8.https://doi.org/10.4085/1062-6050-43 .2.117.

[8] Slobounov S. Injuries In Athletics: Causes and Consequences. New York: Springer; 2008.

[9] Toohey L.A., Drew M.K., Cook J.L., Finch C.F., Gaida J.E. Is subsequent lower limb injury associated with previous injury? A systematic review and metaanalysis. Br J Sports Med 2017;51:1670-8.https://doi.org/10.1136/bjsports-2017 -097500 .

[10] Arnason A., Sigurdsson S.B., Gudmundsson A., Engebretsen L., Bahr R. Risk Factors for Injuries in Football. Am J Sports Med 2004;32:5S-15S. https://doi.org/10.1177 \%2F0363546503258912. 
[11] Rolf C. The Sports Injuries Handbook: Diagnosis and Management. London: A \& C Black; 2007.

[12] Kerr Z.Y., Marshall S.W., Dompier T.P., Corlette J., Klossner D.A., Gilchrist J. College Sports-Related Injuries-United States, 2009-10 Through 2013-14 Academic Years. Morb Mortal Wkly Rep 2015;64:1330-6. https://doi.org/10.15585/mmwr.mm6448a2.

[13] Ristolainen L., Heinonen A., Waller B., Kujala U.M., Kettunen J.A. Gender differences in sport injury risk and types of injuries: a retrospective twelve-month study on cross-country skiers, swimmers, long-distance runners and soccer players. J Sports Sci Med 2009;8:443-51.

[14] Anderson StevenJ. Lower extremity injuries in youth sports. Pediatr Clin North Am 2002;49:627-41. https://doi.org/10. 1016/S0031-3955(02)00010-X.

[15] Welton K.L., Kraeutler M.J., Pierpoint L.A., Bartley J.H., McCarty E.C., Comstock R.D. Injury Recurrence Among High School Athletes in the United States. Orthop J Sports Med 2018;6:1-9.https://doi.org/10.1177/232596711774578

[16] Fuller C.W., Junge A., Dvorak J. A six year prospective study of the incidence and causes of head and neck injuries in international footbal. Br J Sports Med 2005;39:i3-9. https://doi.org/10.1136/bjsm.2005.018937.

[17] Silva R.T.D. Sports injuries of the upper limbs. Rev Bras Ortop 2010;45:122-31.https://doi.org/10.1016/S2255-4971 (15)30280-9.

[18] Rodrigueza A.M., Nogueron G.G., Manriquec D.C., Avila A.B.O. Incidence of injuries among amateur badminton players A cross-sectional study. Medicine 2020;99:1-5. https://doi.org/10.1097/MD.0000000000019785.

[19] Dodson C.C. Prevent, Identify \& Treat Common Volleyball Injuries With These 3 Steps. ROTHMAN 2017. https://rothmanortho.com/stories/blog/common-volleyball-i njuries (accessed April 20, 2020).

[20] Briner W.W., Gallo R. Volleyball Injuries. Sports Medicine n.d.

https://www.urmc.rochester.edu/orthopaedics/sports-medici ne/volleyball-injuries.cfm (accessed November 9, 2020).

[21] Myklebust G. The risk of injury in handball. Sports Medicine n.d.:138-41.
[22] Pocecco E., Ruedl G., Stankovic N., Sterkowicz S., Vecchio F.B.D., García C.G., et al. Injuries in judo: A systematic literature review including suggestions for prevention. Br J Sports Med 2013;47:1139-43. http://dx.doi.org/10.1136/bjs ports-2013-092886.

[23] Pardiwala D.N., Rao N.N., Varshney A.V. Injuries in Cricket. Sports Health 2018;10:217-22. https://doi.org/10.1 $177 / 1941738117732318$

[24] Young C., Lydecker M. Throwing injuries of the upper extremity: Treatment, follow-up care, and prevention. UpToDate 2019.https://www.uptodate.com/contents/throwi ng-injuries-of-the-upper-extremity-treatment-follow-up-car e-and-prevention/print (accessed November 9, 2020).

[25] Fu M.C., Ellenbecker T.S., Renstrom P.A., Windler G.S., Dines D.M. Epidemiology of injuries in tennis players. Current Reviews in Musculoskeletal Medicine 2018;11:1-5. https://doi.org/10.1007/s12178-018-9452-9.

[26] Wanivenhaus F., Fox A.J.S., Chaudhury S., Rodeo S.A. Epidemiology of Injuries and Prevention Strategies in Competitive Swimmers. Sports Health 2012;4:246-51. https://doi.org/10.1177/1941738112442132.

[27] Purcell L., Micheli L. Low Back Pain in Young Athletes. Sports Health 2009;1:212-22. https://doi.org/10.1177/1941 738109334212

[28] Hussain F. Common sporting injuries of lower limb and its management. Br J Sports Med 2010;44:i1-82. http://dx.doi.org/10.1136/bjsm.2010.078725.4.

[29] Sytema R., Dekker R., Dijkstra P.U., Duis H.J.T., Sluis C.K.V.D. Upper Extremity Sports Injury: Risk Factors in Comparison to Lower Extremity Injury in More Than 25000 Cases. Clin J Sport Med 2010;20:256-63. https://doi.org/10.1097/JSM.0b013e3181e71e71.

[30] Brant J.A., Johnson B., Brou L., Comstock R.D., Vu T. Rates and Patterns of Lower Extremity Sports Injuries in All Gender-Comparable US High School Sports. Orthop J Sports Med n.d.;7:1-7. https://doi.org/10.1177/2325967119 873059.

[31] Saunders J., Hungerford B., Roth T.W., Cusi M., Wall H.V.D. Recurrent hamstring injuries in elite athletes - A paradigm shift to mechanical dysfunction of the sacroiliac joint as one causation. International Journal of Human Movement and Sports Sciences 2019;7:33-42. https://doi.org/10.13189/saj.2019.070203 